\title{
Effect of polymer shielding on elution of G3PDH bound to dye-ligand adsorbent
}

\begin{abstract}
Batch binding experiments were performed to assess the recovery performance of glyceraldehyde 3-phosphate dehydrogenase (G3PDH) bound to the unshielded and polymer (polyvinyl pyrrolidone, PVP)-shielded dye-ligand (Cibacron Blue 3GA) adsorbent. The adoption of a polymer-shielded, dye-ligand technique facilitated the elution efficiency of bound G3PDH. It was demonstrated that the recovery of G3PDH using polymer-shielded dye-ligand adsorption yielded higher elution efficiency, at $60.5 \%$ and a specific activity of $42.3 \mathrm{IU} / \mathrm{mg}$, after a low ionic strength elution $(0.15 \mathrm{M} \mathrm{NaCl})$. The unshielded dye-ligand yielded lower elution efficiency, at $6.5 \%$ and a specific activity of $10.2 \mathrm{IU} / \mathrm{mg}$.
\end{abstract}

Keyword: Dye-ligand; Cibacron Blue 3GA; G3PDH; Elution yield; Low ionic strength elution 